\title{
EVIDENCE BASED GUIDELINE FOR THE MANAGEMENT OF HYPERTENSION IN ADULTS: APPROPRIATE APPROACH
}

\section{KARIM ME ${ }^{1}$}

Hypertension is the most common clinical condition seen in day to day practice. If not detected early and treated appropriately, it leads to cardiovascular and renal morbidity and mortality. Patients want to be assured that their blood pressure treatment will reduce their disease burden while physicians want guidance on hypertension management using the best scientific evidence ${ }^{1}$. Clinicians base their practice on the best available evidence which needs to be up to date, relevant, authoritative and easily accessible ${ }^{2}$. Evidence based guidelines is regarded as the best guideline .The new Joint National Committee of USA (JNC-8) is now recommended as the best guideline as it used vigorous evidence based method, i.e. evidence drawn from randomized controlled trials(RCTs) to recommend treatment threshold, goals and medication.

Major differences in the new guidelines (JNC8) from JNC-7 guideline include:

1) Similar treatment goals were defined for all hypertensive populations except when evidence review supported different goals for a particular subpopulation. The same thresholds and goals are recommended for hypertensive adults with diabetes or nondiabetic chronic kidney disease (CKD) as for the general hypertensive population younger than 60 years; 2) four classes of drugs namely thiazide diuretics, angiotensin converting enzyme inhibitor, angiotensin receptor blocker and calcium channel blocker were proposed as reasonable choices of drugs for initial therapy. Beta blockers are not recommended for initial therapy; 3) systolic BP threshold increased from $140 \mathrm{~mm}$ of $\mathrm{Hg}$ to $150 \mathrm{~mm}$ of $\mathrm{Hg}$ for patients aged 60 years and older; 4) recommendation to treat patients with diabetes to a treatment goal of $\mathrm{SBP}<140 \mathrm{~mm}$ of $\mathrm{Hg}$ and $\mathrm{DBP}<90 \mathrm{~mm}$ of $\mathrm{Hg}$.

Although this guideline provides evidence based recommendations for the management of high blood pressure and should meet the clinical needs of most physicians and patients: the management should be highly individualized and should be based on clinical situation and judgment.

\section{References:}

1. James PA, Oparil S, Carter BL, Cushman WC, Dennison-Himmelfarb C, Handler J, et al. 2014 Evidence-based guideline for the management of high blood pressure in adults - Report from the panel members appointed to the eighth joint national committee (JNC-8). JAMA 2014; 311(5): 507-20.

2. Davidson's principles and practice of medicine. $22^{\text {nd }}$ ed. London: Elsevier Saunders; p.17.

1. Professor Md. Enamul Karim, Professor of Medicine, Dhaka Medical College \& Hospital, Dhaka. 